OPEN ACCESS

Edited by:

Tao Zeng,

Shandong University, China

Reviewed by:

Runqiu Jiang,

Naniing University, China

Antonio Pesce,

Delta Hospital, Italy

${ }^{*}$ Correspondence:

Fei-Xiang Wu

feixiangwu@hotmail.com

Specialty section:

This article was submitted to

Gastrointestinal and Hepatic

Pharmacology,

a section of the journal

Frontiers in Pharmacology

Received: 08 October 2021 Accepted: 03 November 2021 Published: 18 November 2021

Citation:

$L i Y$-R, Meng $X-Y$, Zong $R-Q$ and Wu F-X (2021) Association Between Procalcitonin and Post-hepatectomy Liver Failure in Hepatocellular

Carcinoma Patients.

Front. Pharmacol. 12:791322.

doi: 10.3389/fphar.2021.791322

\section{Association Between Procalcitonin and Post-hepatectomy Liver Failure in Hepatocellular Carcinoma Patients}

\author{
Yi-Ran Li, Xiao-Yan Meng, Rui-Qing Zong and Fei-Xiang Wu *
}

Department of Intensive Care Medicine, Eastern Hepatobiliary Surgery Hospital, The Third Affiliated Hospital of Naval Medical University, Shanghai, China

Objectives: Procalcitonin (PCT) has long been proved as an early diagnostic signal for postoperative outcomes. The purpose of this study is to explore the value of serum procalcitonin levels in predicting post-hepatectomy liver failure (PHLF), and further to declarethe relationship between postoperative PCT and short-term prognosis in patients after hepatectomy.

Methods: Clinical data of patients with hepatocellular carcinoma (HCC) who underwent hepatectomy from June 1st, 2019 to September 31st, 2020 at Shanghai Eastern Hepatobiliary Surgery Hospital had been retrospectively analyzed. Logistic regression analysis was used to evaluate the risk factors related to PHLF. The Kaplan-Meier method was used to calculate the PHLF rate and 30-day survival after surgery.

Results: A total of 885 patients with complete data were finally included in analysis, 311 of them with elevated serum PCT $(\geq 1 \mathrm{ng} / \mathrm{ml}$ ). Results of the logistic regression analysis suggested a significant association between PCT and PHLF [HR, 95\%Cl; 3.801 (1.825, 7.917), $p<0.001$ ]. Other significant risk factors for PHLF included portal hypertension, portal blocking time (>30 min) and blood transfusion (>200 ml). Kaplan-Meier analysis also suggested a higher PHLF rate in elevated PCT patients $[9.0 \%(95 \% \mathrm{Cl}, 7.3$ to $12.8 \mathrm{VS}$. $1.9 \%(95 \% \mathrm{Cl}, 1.1-4.3)) ; p<0.001]$. For secondary outcomes, elevated PCT was also highly associated with postoperative sepsis, ICU admission, 30-day mortality and 3-month mortality.

Conclusion: Elevated procalcitonin level in patients after hepatectomy is related to higher PHLF rate, with lower 30-day survival and poor short-term postoperative outcomes.

Keywords: procalcitonin, post-hepatectomy liver failure, hepatocellular carcinoma, biomarker, mortality

\section{INTRODUCTION}

Procalcitonin (PCT) is a prohormone of 116-amino acid peptides (Maruna et al., 2000). In healthy individuals, PCT is produced by thyroidal and adipose tissue, and could further be cleaved to form calcitonin for maintaining serum calcium homeostasis. The normal serum value of PCT is $<0.05 \mathrm{ng} /$ $\mathrm{ml}$, while a higher serum level of PCT could be a sign of a serious bacterial infection (Meisner, 2002). Thus, PCT has been deemed as an infection biomarker that can effectively guide the use of antibiotics in critically ill patients, while more literature has reported that elevated PCT levels could be 
associated with other long and short-term outcomes after surgery (Sponholz et al., 2006; Engel et al., 2013). For instance, PCT levels can be elevated in patients with hepatitis, cirrhosis and liver failure.

Liver resection is an effective treatment for primary liver cancer. Postoperative monitoring of PCT can guide the use of antibiotics, and be further applied to control postoperative infections and to reduce postoperative complications as well (Jones et al., 2007). PCT could rise within $4 \mathrm{~h}$ after infection or injury, and drop back to baseline in 2-3 days, this character makes it a sensitive indicator for clinical use in disease detection. Previous literature reports that PCT is acceptable for predicting infection in patients with liver disease (Lin et al., 2014). At present, there are few reports have detected the value of PCT in indicating outcomes after hepatectomy, and the diagnostic cutoff value of PCT in liver diseaseremains controversial (Jody et al., 2015).

The present study aims to determine whether postoperative serum PCT level is associated with and post-hepatectomy liver failure (PHLF) and other short-term outcomes in patients diagnosed with hepatocellular carcinoma (HCC) after hepatectomy.

\section{MATERIALS AND METHODS}

\section{Patients and Methods}

We retrospectively identified all patients who underwent hepatectomy from June 1st, 2019 to September 31st, 2020 at Shanghai Eastern Hepatobiliary Surgery Hospital. Patients were included using the following inclusion criteria: (a) patients with HCC who received hepatectomy; all diagnoses were confirmed by pathological examination of the surgical specimen; (b) age of 18-80 years; and (c) Child-Pugh A or B. Exclusion criteria were as follows: (1) patients with a history of any other malignant tumor before hepatectomy; (2) without or unavailable postoperative PCT data; (3) incomplete data recording of postoperative outcome; (4) without informed consent. This study was approved by the local ethics committee. Written informed consent was obtained from all participants.

\section{Data Collection}

All data were based on hospital medical records and clinical follow-up, the last follow-up data were January 31, 2021. The primary outcome of this study was the rate of PHLF. Liver failure was defined as a total bilirubin level of $\geq 5 \mathrm{mg} / \mathrm{dl}$ or prothrombin time of $<40 \%$ due to exacerbation of the background liver disease.

Secondary outcomes include postoperative sepsis/septic shock, ICU admission, other organ dysfunctions except for liver, reoperation for any surgical adverse event, 30-day mortality and 3-month mortality.

The serum PCT levels were measured in serum samples. Samples were acquired at $12 \mathrm{~h}$ after surgery and then stored at $-80^{\circ} \mathrm{C}$ using an automated PCT immunoassay (Elecsys BRAHMS PCT; Roche Diagnostics GmbH, Mannheim, Germany). The detection limit was $0.01 \mathrm{ng} / \mathrm{ml}$.

\section{Statistical Analysis}

Continuous variables were presented as mean \pm SD or median with IQR (interquartile range). Categorical variables were grouped based on clinical findings, presented as counts and percentages. Patients were divided into two groups according to the measured PCT. A measured serum PCT value $>1 \mathrm{ng} / \mathrm{ml}$ was defined as elevated PCT according to previous researches, while each measured PCT value was also applied in the analysis as additional evidence. Student $\mathrm{t}$ test, Fisher exact test or Chisquared test were used accordingly. A univariate logistic regression model for all variables potentially associated PHLF has been applied, then a multivariable analysis was further applied using selected variables with $p<0$.1in the univariate analysis, using a backward stepwise selection process. The Kaplan-Meier method was used to calculate the recipient and graft survival, and subgroup analysis was then applied according to the risk factors. The significance level was set as $p<0.05$ at two tails. All statistical analyses were performed using the SPSS version 25.0 software program (IBM SPSS, Chicago, IL) and R version 4.0.3 software (Institute for Statistics and Mathematics, Vienna, Austria; http://www.r-project.org/).

\section{RESULTS}

From June 1st'2019 to September 31st' 2020, a total of 1,123 patients underwent liver resection for HCC in Eastern Hepatobiliary Surgical Hospital. After screening, 885 of them were feasible for analysis with sufficient clinical data and assigned informed consent. After PCT measurement, 574 patients had a measured serum PCT level of less than $1 \mathrm{ug} /$ $\mathrm{mL}$, while 311 of them with comparatively higher serum PCT $(\geq 1 \mathrm{ug} / \mathrm{mL}$ ). The study flow was presented in Figure 1. The baseline characteristics and operative variables of the patients in the training cohort were listed in Table 1. Similar results were presented in most baseline variables, however, in terms of disease-related or operative variables, significant differences existed in DM, tumor number, tumor size, portal hypertension, ascites, blood loss (over $500 \mathrm{ml}$ or less), blood transfusion (over $200 \mathrm{ml}$ or less) and liver resection (over three liver segments or less).

For the primary outcome, a total of 39 patients had been diagnosed of PHLF, among them, 28 patients have a measured $\mathrm{PCT} \geq 1 \mathrm{ng} / \mathrm{ml}$. In the univariate analysis, nine variables were screened out as potential risk factors for PHLF with unadjusted $p$ value $<0.1$, there were elevated serum PCT level (measured serum PCT value as well), cirrhosis, ascites, portal hypertension, tumor number, blood loss, blood transfusion and liver resection range (Table 2). Further, we applied these nine variables into a multivariable analysis, ultimately four variables were included in the model (Table 3). Both of categorical variable of PCT $(\geq 1 \mathrm{ng} / \mathrm{ml})$ and measured value of PCT exhibited significant relation with the PHLF events [HR, 95\%CI; 3.801 (1.825, 7.917), $p<$ $0.001 ; 1.05$ (1.017, 1.085), $p=0.003$ ]. Other Signiant risk factors included portal hypertension, portal blocking time $(>30 \mathrm{~min})$ and blood transfusion $(>200 \mathrm{ml})$ (Table 3). 


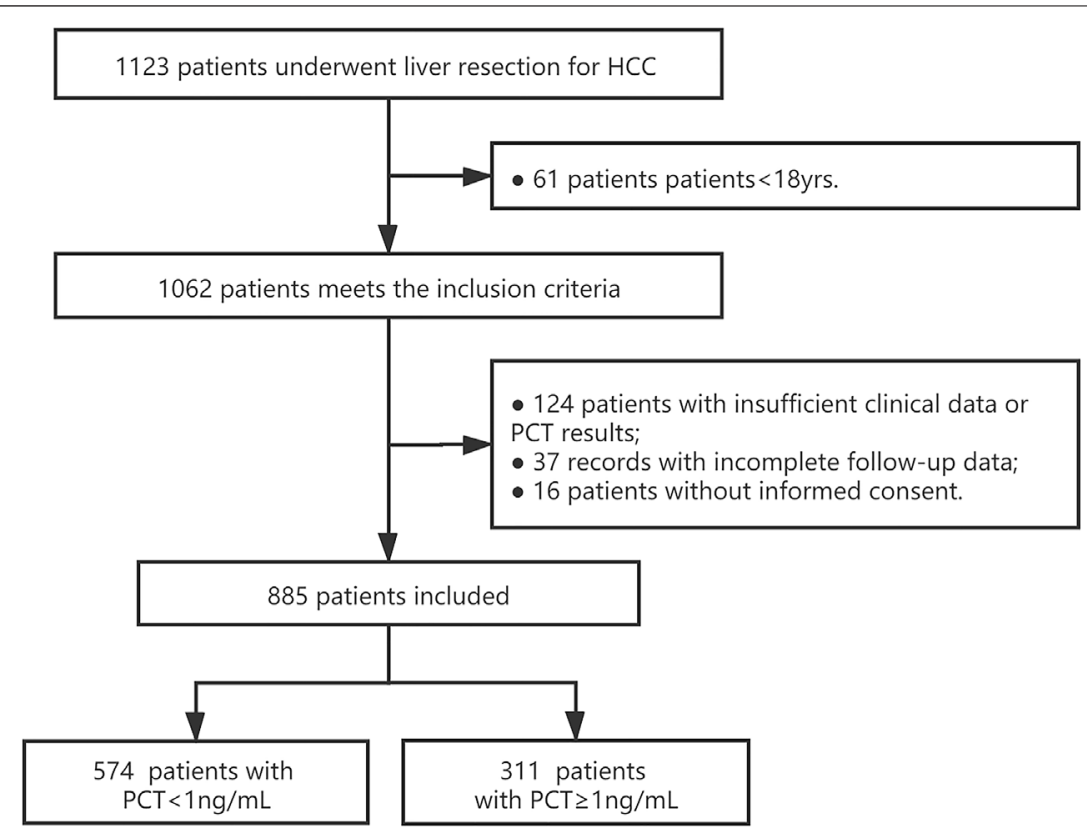

FIGURE 1 | Study flow. PCT: procalcitonin; HCC: hepatoma carcinoma cell.

TABLE 1 | Baseline Characteristic and operative variables.

\begin{tabular}{|c|c|c|c|}
\hline Variable No. (\%) & $\begin{array}{c}\mathrm{PCT}<1 \mathrm{ng} / \mathrm{ml} \\
(\mathrm{N}=574)\end{array}$ & $\begin{array}{c}\mathrm{PCT} \geq 1 \mathrm{ng} / \mathrm{ml} \\
(\mathrm{N}=311)\end{array}$ & $p$ Value \\
\hline PCT, median (IQR), ng/mL & $0.13(0.29,0.59)$ & $1.1(1.0,5.9)$ & - \\
\hline Gender, female & $117(20.4)$ & $63(20.3)$ & 0.965 \\
\hline Age,mean (SD),yr & $55.5 \pm 11.6$ & $57.5 \pm 12.2$ & 0.227 \\
\hline Hypertension & $129(22.5)$ & $83(26.7)$ & 0.226 \\
\hline DM & 59 (10.3) & $46(14.8)$ & 0.048 \\
\hline Smoking history & $238(41.5)$ & $125(40.2)$ & 0.714 \\
\hline Drinking history & $184(32.1)$ & $91(29.3)$ & 0.391 \\
\hline Tumor number, multiple & $89(15.5)$ & $62(19.9)$ & 0.094 \\
\hline Tumor size, $>5 \mathrm{~cm}$ & $231(40.2)$ & $164(52.7)$ & $<0.001$ \\
\hline Antivirus & $209(36.4)$ & $107(34.4)$ & 0.632 \\
\hline HBV-DNA, $\geq 501 \mathrm{U} / \mathrm{m}$ & $249(43.4)$ & $141(45.3)$ & 0.575 \\
\hline Cirrhosis & $274(47.7)$ & $158(50.8)$ & 0.383 \\
\hline Portal hypertension & $102(17.8)$ & $71(22.8)$ & 0.070 \\
\hline Ascites & $54(9.4)$ & $46(14.8)$ & 0.016 \\
\hline Portal blocking time,>30min & $133(232.2)$ & $80(37.6)$ & 0.396 \\
\hline Blood loss,>500 ml & $113(19.7)$ & $102(32.8)$ & $<0.001$ \\
\hline Blood transfusion,>200 ml & $103(17.9)$ & $107(34.4)$ & $<0.001$ \\
\hline Liver resection range, $\geq 3$ segment & $172(30)$ & $117(37.6)$ & 0.025 \\
\hline Peritoneoscope & $16(2.8)$ & $8(2.6)$ & 0.851 \\
\hline
\end{tabular}

Abbreviation: PCT: procalcitonin; SD, standard deviation; DM, diabeties mellitus.

Besides, the ROC curves for serum value of PCT, model one and model two of multivariate logistic regression analysis was presented in Figure 2, a promising predictive value of them for PHLF was revealed.

In terms of secondary outcomes, an unadjusted logistic regression analysis suggested that a postoperative serum PCT value over $1 \mathrm{ng} / \mathrm{ml}$ was significant associated with postoperative sepsis [HR, 95\%CI; 7.398 (4.921, 11.121); $p<0.001]$, ICU admission [HR, 95\%CI; 4.346 (1.868, 10.115); $p=0.001$ ], 30- day mortality [HR, 95\%CI; $6.979(1.932,25.207) ; p=0.003]$ and 3 -month mortality [HR, 95\%CI; 4.976 (2.055, 12.049); $p<0.001$ ]. No significance has been found between PCT with severe adverse events or reoperation (Table 4). Kaplan-Meier analysis was also applied for analysis of elevated serum PCT level (>1 ng/ $\mathrm{ml}$ ) with PHLF and mortality. The results showed that, compare with PCT less than $1 \mathrm{ng} / \mathrm{ml}$, an elevated serum PCT level $(>1 \mathrm{ng} / \mathrm{ml})$ was associated with a higher PHLF

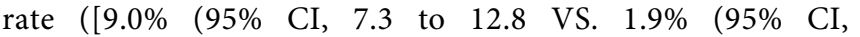


TABLE 2 | Univariate and multivariate analyses for risk factors associated with PHLF.

\begin{tabular}{|c|c|c|}
\hline Variable & $\begin{array}{c}\text { Hazard } \\
\text { ratio }(95 \% \mathrm{Cl})\end{array}$ & $p$ Value \\
\hline PCT ( $\geq 1$ vs. $<1$ ng/ml) & $5.064(2.485,10.319)$ & $<0.001$ \\
\hline $\mathrm{PCT}^{*}$ & $1.092(1.057,1.129)$ & $<0.001$ \\
\hline Sex (male vs. female) & $0.435(0.153,1.240)$ & 0.119 \\
\hline Age (year) & $0.989(0.964,1.015)$ & 0.414 \\
\hline Hypertension & $1.059(0.659,1.703)$ & 0.812 \\
\hline DM & $1.353(0.552,3.316)$ & 0.509 \\
\hline Smoking history & $1.025(0.465,2.262)$ & 0.951 \\
\hline Drinking history & $1.729(0.777,3.843)$ & 0.179 \\
\hline Surgical history & $0.68(0.159,2.901)$ & 0.602 \\
\hline Cirrhosis & $2.45(1.225,4.900)$ & 0.011 \\
\hline Portal hypertension & $3.053(1.576,5.913)$ & 0.001 \\
\hline Ascites & $2.115(0.944,4.739)$ & 0.069 \\
\hline Tumor number (multiple vs single) & $3.664(1.886,7.117)$ & $<0.001$ \\
\hline Tumor size ( $>5$ vs. $\leq 5, \mathrm{~cm}$ ) & $1.066(0.56,2.030)$ & 0.845 \\
\hline Portal blocking time (>30 vs. $\leq 30$, min) & $2.563(1.334,4.922)$ & 0.005 \\
\hline Blood loss (>500 vs. $\leq 500, \mathrm{ml}$ ) & $3.921(2.048,7.508)$ & $<0.001$ \\
\hline Blood transfusion (>200 vs. $\leq 200, \mathrm{ml}$ ) & $5.677(2.919,11.041)$ & $<0.001$ \\
\hline Liver resection ( $\geq 3$ vs. $<3$ segment) & $1.784(0.941,3.380)$ & 0.076 \\
\hline Antivirus & $0.607(0.292,1.262)$ & 0.182 \\
\hline HBV DNA ( $\geq 50$ vs. $<50 \mathrm{IU} / \mathrm{ml})$ & $1.216(0.64,2.312)$ & 0.55 \\
\hline
\end{tabular}

The bold values represent the statistical significance of the data.

TABLE 3 | Multivariate analyses for risk factors associated with PHLF.

$\begin{array}{lcc}\text { Variable } & \text { Hazard } & p \text { Value } \\ \text { ratio }(95 \% \mathrm{Cl}) & \end{array}$

Model 1

PCT

Portal hypertension

Portal blocking time (>30 vs. $\leq 30$, min)

Blood transfusion (>200 vs. $\leq 200, \mathrm{ml}$ )

Model 2

$\mathrm{PCT}^{*}$

Portal hypertension

Portal blocking time (>30 vs. $\leq 30$, min)

Blood transfusion (>200 vs. $\leq 200, \mathrm{ml}$ )

$\begin{array}{cc}3.801(1.825,7.917) & 0.000 \\ 2.973(1.473,6.003) & 0.002 \\ 2.369(1.181,4.751) & 0.015 \\ 3.937(1.973,7.853) & 0.000 \\ & \\ 1.05(1.017,1.085) & 0.003 \\ 3.305(1.634,6.683) & 0.001 \\ 2.639(1.307,5.327) & 0.007 \\ 4.246(2.13,8.464) & 0.000\end{array}$

1.1-4.3)); $p<0.001$, Figure 3A]). Besides, elevated serum PCT level $(>1 \mathrm{ng} / \mathrm{ml})$ was also associated with a higher 3 -month mortality rate ([5.8\% (95\% CI, 2.6 to 9.5 VS. $1.2 \%$ (95\% CI, $1.0-2.3) ; p=0.001$, Figure 3B]).

\section{DISCUSSION}

PHLF is the most important cause of morbidity after hepatectomy. Early diagnosis and prompt treatment of postoperative infection can improve the prognosis of patients. Therefore, we need a clinical diagnostic index that can predict PHLF after hepatectomy and prepare ahead of schedule for more intensive medical care (Angele and Faist, 2002; Owens and Stoessel, 2008). According to previous researches, PCT levels are elevated in bacterial, parasites, and infections, and the PCT is suitable for the diagnosis of infection. The early use of antibiotics is emphasized in the Sepsis Guidelines, which is closely related to the mortality rate of patients. As a useful biomarker, PCT can even distinguish some severe complications after surgery.

For surgical patients with pre-existing liver diseases or scheduled for hepatectomy, PCT could also be valuable in anticipating surgical outcomes. Patients with liver disease, especially cirrhosis, are prone to bacterial infection, thus early diagnosis of infection in patients with underlying liver diseases is necessary (Elefsiniotis et al., 2006). Besides, in 2 days after abdominal surgery, the value of PCT is increased due to bile leakage of residual liver, causing abdominal bacteria pollution, which may lead to local or systemic infections (Meisner et al., 1998; Jekarl et al., 2013). An accurate PCT cut-off value for postoperative outcomes is very important to avoid overtreatment or misdiagnosis. It is well known that the PCT cut-off value of $0.5 \mathrm{ng} / \mathrm{ml}$ was considered significant for sepsis diagnosis. Previous research, the PCT concentration $\geq 1.8 \mathrm{ng} / \mathrm{ml}$ for two consecutive days has predictive significance with best sensitivity and specificity for severe postoperative adverse events (Rau et al., 2000; Mofidi et al., 2009; Adachi et al., 2015; Chen et al., 2017).
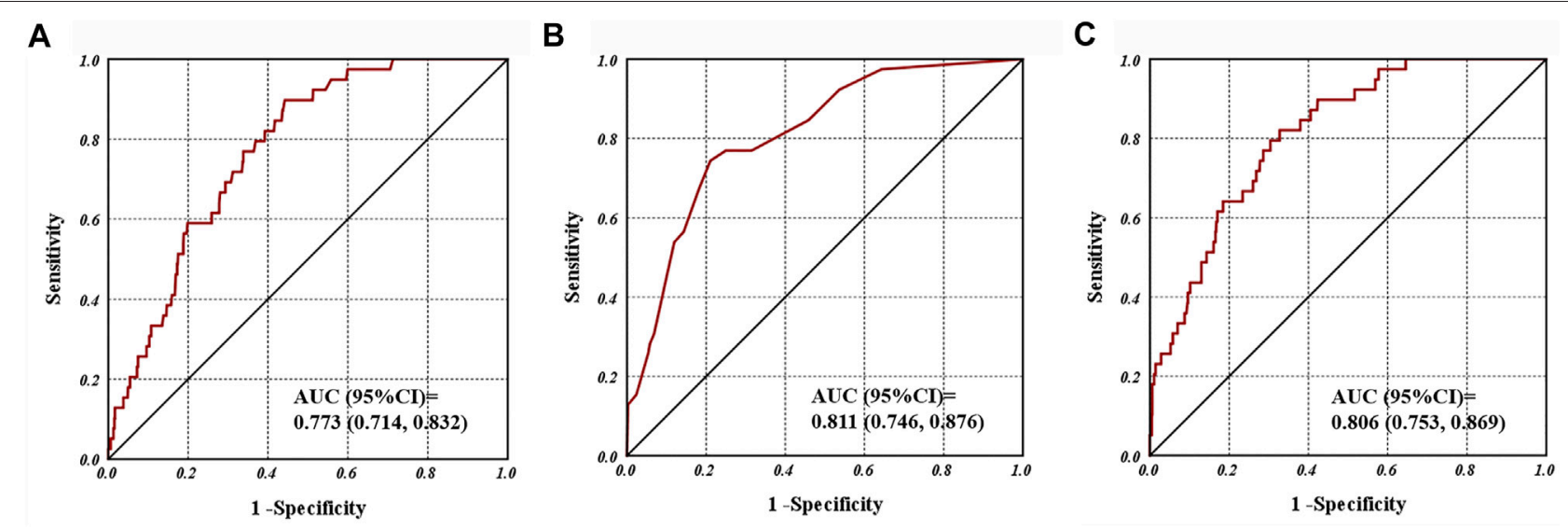

FIGURE 2 | Receiver operating characteristic curves for (A) post-operative serum procalcitonin; (B) model 1; (C) and model 2 associated with post-hepatectomy liver failure. 
TABLE 4 | Secondaryoutcomes.

\begin{tabular}{|c|c|c|c|c|}
\hline & $\begin{array}{c}\mathrm{PCT}<1 \mathrm{ng} / \mathrm{ml} \\
(\mathrm{N}=574)\end{array}$ & $\begin{array}{c}\mathrm{PCT}<1 \mathrm{ng} / \mathrm{ml} \\
(\mathrm{N}=311)\end{array}$ & $\begin{array}{c}\text { Hazard } \\
\text { ratio }(95 \% \mathrm{Cl})\end{array}$ & $p$ Value \\
\hline Sepsis/septic shock (\%) & $37(6.4)$ & $105(33.8)$ & $7.398(4.921,11.121)$ & $<0.001$ \\
\hline ICU admission (\%) & $8(1.4)$ & $16(5.5)$ & $4.346(1.868,10.115)$ & 0.001 \\
\hline Organ disfunction $^{a}(\%)$ & $33(5.7)$ & $21(6.8)$ & $1.187(0.674,2.093)$ & 0.552 \\
\hline Reoperation (\%) & $6(1.0)$ & $8(2.7)$ & $1.862(0.596,5.824)$ & 0.285 \\
\hline 30-day mortality (\%) & $3(0.5)$ & $11(3.5)$ & $6.979(1.932,25.207)$ & 0.003 \\
\hline 3-month mortality (\%) & $7(1.2)$ & $18(5.8)$ & $4.976(2.055,12.049)$ & $<0.001$ \\
\hline
\end{tabular}

ather organ disfunction except for liver. Abbreviation: PCT, procalcitonin; Cl: confidence interval.
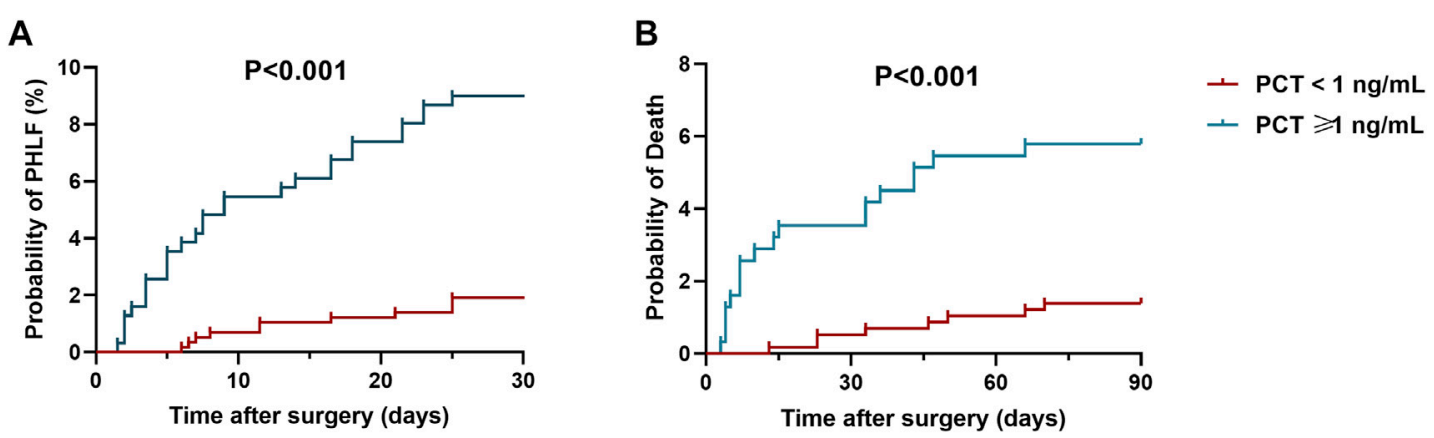

FIGURE 3 | Kaplan-Meier analysis for post-operative procalcitonin on (A) post-hepatectomy liver failure rate; (B) 3-month mortality.

The half-life of serum procalcitonin was $20-24 \mathrm{~h}$, this study chose a time point of PCT on the first day after surgery as the research time. The previous literature also reports that a PCT value $\geq$ $0.5 \mathrm{ng} / \mathrm{ml}$ may indicate that this insult still exists in the possible evolution of postoperative infections after $24 \mathrm{~h}$ of surgery. However, non-infectious factors after the operation cause the PCT value to increase, and it is difficult to find a suitable PCT cut-off value to diagnose other surgical complications. Previous literature has shown that a PCT cut-off value of $\geq 1 \mathrm{ng} / \mathrm{ml}$ can diagnose infection on the first day after surgery (Mokart et al., 2005a; Mokart et al., 2005b).

In the present study, we determined that elevated serum PCT levels $(>1 \mathrm{ng} / \mathrm{ml})$ are independently associated with increased incidence of PHLF in patients who underwent hepatectomy for HCC. As the importance of diagnostic clinical algorithm in decision-making in HCC patients, Barcelona Clinic Liver Cancer (BCLC) was to analyze the possible prognostic factors of the outcome (Llovet et al., 1999; Trovato et al., 2013). PCT value could be used for example to implement the BCLC and to predict PHLF and short-term outcomes after hepatectomy for HCC patients. However, the reasons underlying the correlation of PCT value and PHLF remain unclear. Our findings also demonstrated that increased serum PCT levels were present in patients with several of the complications including portal hypertension, ascites and larger tumor size. These results are in line with previous reports that the serum PCT levels were higher in the patients with alcoholic liver cirrhosis and portal hypertension due to various digestive diseases. Besides, Evidence has proved that portal hypertension could worsen bacterial translocation by increasing intestinal permeability, while other findings have shown that patients with cirrhosis and ascites have higher rates of bacterial infections than patients with nonalcoholic liver disease (Rau et al., 2000; Chen et al., 2017). These pieces of evidence suggest that bacteremia, or even sepsis, is common in patients with elevated PCT, and severely infected patients are at high risk for PHLF. Thus, the existence of bacteremia or even sepsis might play a core role in those PHLF patients with elevated PCT. However, the patient's background varies based on the cause of hospitalization and etiology, therefore, it might be difficult to implicitly conclude as serum PCT levels differ based on the cause of infection. Specially, the reason for the elevated serum PCT levels in patients without bacterial infection remains unclear.

In our study, increased PCT value is also seen in other complications of hepatectomy besides PHLF. First of all, the increased incidence of sepsis or septic shock is higher in patients with elevated PCT. Besides, results also show that patients with elevated PCT values have higher 30-day mortality as well as 3month mortality, with more risks for ICU admission. These results are in line with conclusions from previous studies that PCT assay may help identify complications in patients after hepatectomy, and predict short-term prognosis. For instance, the PCT value is elevated in complications of liver cirrhosis. Furthermore, PCT assessment may potentially help physicians to limit the number of prescriptions for antibiotics. Other diseases associated with elevated PCT include cardiogenic 
shock, severe pancreatitis, severe renal dysfunction, ALF, liver transplantation in children, and these diseases all suggest a poor prognosis (Rey et al., 2007; Minami, 2014; Patout et al., 2014; Sugihara et al., 2017; Tschiedel et al., 2018). Previous studies have also indicated that an elevated PCT value is associated with complications and poor prognosis after hepatectomy, yet its underlying mechanism remains unknown (Kretzschmar et al., 2001).

Several limitations of this study should be mentioned. Firstly, this is a retrospective study involving a relatively small sample size; therefore, a multi-center patient cohort is needed for further validation of our results. Second, several potential risk factors for PHLF are not analyzed in this trial, including serum CPR level and tumor markers. Besides, the causes of elevated PCT in patients with poor prognosis have not been investigated in this research.

\section{CONCLUSION}

In conclusion, we determined that an elevated serum PCT level of patients after hepatectomy has a high predictive value for PHLF, as well as other severe postoperative short-term outcomes, including mortality and ICU admission. Postoperative serum PCT could be an effective biomarker for the prediction of outcomes and instruction of further intensive medication.

\section{REFERENCES}

Adachi, T., Kishihara, Y., Okano, H., Honzawa, H., Hirayama, M., Higashi, H., et al. (2015). The Utility of Procalcitonin for the Patients with Infected Pancreatic Necrotic and Pancreatic Abscess. Intensive Care Med. Exp. 3, 1-2. doi:10.1186/ 2197-425x-3-s1-a113

Angele, M. K., and Faist, E. (2002). Clinical Review: Immunodepression in the Surgical Patient and Increased Susceptibility to Infection. Crit. Care 6, 298-305. doi:10.1186/cc1514

Chen, H. Z., Ji, L., Li, L., Wang, G., Bai, X. W., Cheng, C. D., et al. (2017). Early Prediction of Infected Pancreatic Necrosis Secondary to Necrotizing Pancreatitis. Medicine (Baltimore) 96, e7487. doi:10.1097/ MD.0000000000007487

Elefsiniotis, I. S., Petrocheilou, A., Scarmeas, N., Ketikoglou, I., Pantazis, K. D., Toutouza, M., et al. (2006). Serum Procalcitonin Levels in Chronic Hepatitis C Patients under Pegylated Interferon-Alpha Plus Ribavirin Treatment. J. Clin. Virol. 37, 329-331. doi:10.1016/j.jcv.2006.08.014

Engel, H., Ben Hamouda, N., Portmann, K., Delodder, F., Suys, T., Feihl, F., et al. (2013). Serum Procalcitonin as a Marker of post-cardiac Arrest Syndrome and Long-Term Neurological Recovery, but Not of Early-Onset Infections, in Comatose post-anoxic Patients Treated with Therapeutic Hypothermia. Resuscitation 84, 776-781. doi:10.1016/j.resuscitation.2013.01.029

Jekarl, D. W., Lee, S. Y., Lee, J., Park, Y. J., Kim, Y., Park, J. H., et al. (2013). Procalcitonin as a Diagnostic Marker and IL-6 as a Prognostic Marker for Sepsis. Diagn. Microbiol. Infect. Dis. 75, 342-347. doi:10.1016/ j.diagmicrobio.2012.12.011

Jody, C., Hynan, N., Attar, C., and Sanders, C. (2015). "Procalcitonin Identifies Cell Injury, Not Bacterial Infection, in Acute Liver Failure. Plos One 10, e01385666. doi:10.1371/journal.pone.0138566

Jones, A. E., Fiechtl, J. F., Brown, M. D., Ballew, J. J., and Kline, J. A. (2007). Procalcitonin Test in the Diagnosis of Bacteremia: A Meta-Analysis. Ann. Emerg. Med. 50, 34-41. doi:10.1016/j.annemergmed.2006.10.020

\section{DATA AVAILABILITY STATEMENT}

The raw data supporting the conclusion of this article will be made available by the authors, without undue reservation.

\section{ETHICS STATEMENT}

The studies involving human participants were reviewed and approved by The ethics committee of Eastern Hepatobiliary Surgery Hospital. The patients/participants provided their written informed consent to participate in this study.

\section{AUTHOR CONTRIBUTIONS}

Study concept and design: X-YM, Y-RL, and F-XW. Drafting of the manuscript: Y-RL, X-YM, and F-XW. Acquisition of data, analysis and interpretation of data: Y-RL, and R-QZ. Critical revision of the manuscript: X-YM and Y-RL. Statistical analysis: Y-RL. All authors have read and approved the final manuscript.

\section{FUNDING}

This study was supported by the National Natural Science Foundation of China; 81972574 (Guang-Zhi Jin).

Kretzschmar, M., Krüger, A., and Schirrmeister, W. (2001). Procalcitonin Following Elective Partial Liver Resection-Oorigin from the Liver? Acta Anaesthesiol Scand. 45, 1162-1167. doi:10.1034/j.1399-6576.2001.450918.x

Lin, K. H., Wang, F. L., Wu, M. S., Jiang, B. Y., Kao, W. L., Chao, H. Y., et al. (2014). Serum Procalcitonin and C-Reactive Protein Levels as Markers of Bacterial Infection in Patients with Liver Cirrhosis: a Systematic Review and MetaAnalysis. Diagn. Microbiol. Infect. Dis. 80, 72-78. doi:10.1016/ j.diagmicrobio.2014.03.029

Llovet, J. M., Brú, C., and Bruix, J. (1999). Prognosis of Hepatocellular Carcinoma: the BCLC Staging Classification. Semin. Liver Dis. 19, 329-338. doi:10.1055/s2007-1007122

Minami, E. (2014). Markedly Elevated Procalcitonin in Early Postoperative Period in Pediatric Open Heart Surgery: a Prospective Cohort Study. J. Intensive Care 2, 38 .

Maruna, P., Nedelníková, K., and Gürlich, R. (2000). Physiology and Genetics of Procalcitonin. Physiol. Res. 49 Suppl 1 (Suppl. 1), S57-S61.

Meisner, M. (2002). Pathobiochemistry and Clinical Use of Procalcitonin. Clin. Chim. Acta 323, 17-29. doi:10.1016/s0009-8981(02)00101-8

Meisner, M., Tschaikowsky, K., Hutzler, A., and Schick, J. S. (1998). Postoperative Plasma Concentrations of Procalcitonin after Different Types of Surgery. Intensive Care Med. 24. 680. doi:10.1007/s001340050644

Mofidi, R., Suttie, S. A., Patil, P. V., Ogston, S., and Parks, R. W. (2009). The Value of Procalcitonin at Predicting the Severity of Acute Pancreatitis and Development of Infected Pancreatic Necrosis: Systematic Review. Surgery 146, 72-81. doi:10.1016/j.surg.2009.02.013

Mokart, D., Merlin, M., Sannini, A., Brun, J. P., Delpero, J. R., Houvenaeghel, G., et al. (2005b). Procalcitonin, Interleukin 6 and Systemic Inflammatory Response Syndrome (SIRS): Early Markers of Postoperative Sepsis after Major Surgery. Br. J. Anaesth. 94, 767-773. doi:10.1093/bja/aei143

Mokart, M., Sannini, J. P., Brun, J. R., Houvenaegheland Moutardier (2005a). Procalcitonin, Interleukin 6 and Systemic Inflammatory Response Syndrome (SIRS): Early Markers of Postoperative Sepsis after Major Surgery. Br. J. Anaesth 26, S159-S164. doi:10.1093/bja/aei143 
Owens, C. D., and Stoessel, K. (2008). Surgical Site Infections: Epidemiology, Microbiology and Prevention. J. Hosp. Infect. 70 Suppl 2, 3-10. doi:10.1016/ S0195-6701(08)60017-1

Patout, M., Salaün, M., Brunel, V., Bota, S., Cauliez, B., and Thiberville, L. (2014). Diagnostic and Prognostic Value of Serum Procalcitonin Concentrations in Primary Lung Cancers. Clin. Biochem. 47, 263-267. doi:10.1016/j.clinbiochem.2014.09.002

Rau, S., Baumgart, G., and Grünert, G. (2000). The Clinical Value of Procalcitonin in the Prediction of Infected Necrosis in Acute Pancreatitis. Intensive Care Med. 94, 767-773.

Rey, C., Los Arcos, M., Concha, A., Medina, A., Prieto, S., Martinez, P., et al. (2007). Procalcitonin and C-Reactive Protein as Markers of Systemic Inflammatory Response Syndrome Severity in Critically Ill Children. Intensive Care Med. 33, 477-484. doi:10.1007/s00134-006-0509-7

Sponholz, C., Sakr, Y., Reinhart, K., and Brunkhorst, F. (2006). Diagnostic Value and Prognostic Implications of Serum Procalcitonin after Cardiac Surgery: A Systematic Review of the Literature. London: Critical Care.

Sugihara, T., Koda, M., Okamoto, T., Miyoshi, K., Matono, T., Oyama, K., et al. (2017). Serum Procalcitonin in Patients with Acute Liver Failure. Yonago Acta Med. 60, 40-46. doi:10.33160/yam.2017.06.006

Trovato, M. A., Pesce, A., Sofia, M., Montineri, A., Basile, A., Palermo, F., et al. (2013). Is BCLC Algorithm Useful in Clinical Practice? Study on 164 HCC Patients. Hepatogastroenterology 60, 1742-1745. doi:10.5754/hge11768
Tschiedel, E., Assert, R., Felderhoff-Müser, U., Kathemann, S., Witzke, O., Hoyer, P., et al. (2018). Undue Elevation of Procalcitonin in Pediatric Paracetamol Intoxication Is Not Explained by Liver Cell Injury Alone. Ann. Hepatol. 17, 631-637. doi:10.5604/01.3001.0012.0932

Conflict of Interest: The authors declare that the research was conducted in the absence of any commercial or financial relationships that could be construed as a potential conflict of interest.

Publisher's Note: All claims expressed in this article are solely those of the authors and do not necessarily represent those of their affiliated organizations, or those of the publisher, the editors and the reviewers. Any product that may be evaluated in this article, or claim that may be made by its manufacturer, is not guaranteed or endorsed by the publisher.

Copyright (c) $2021 \mathrm{Li}$, Meng, Zong and Wu. This is an open-access article distributed under the terms of the Creative Commons Attribution License (CC BY). The use, distribution or reproduction in other forums is permitted, provided the original author(s) and the copyright owner(s) are credited and that the original publication in this journal is cited, in accordance with accepted academic practice. No use, distribution or reproduction is permitted which does not comply with these terms. 